\title{
Parkinson's Disease and Segmental Coordination during Turning: II. Walking Turns
}

\author{
Sakineh Akram, James S. Frank, Mandar Jog
}

\begin{abstract}
Objective: Individuals with Parkinson's disease (PD) show poorer balance and greater incidence of falls while turning. We investigated whether a disturbance in timing and sequence of reorientation of body segments is a potential cause of turning difficulty in PD and is altered by levodopa. Methods: The sequence and timing of segmental reorientation during $45^{\circ}$ and $90^{\circ}$ walking turns were recorded in nineteen healthy controls and fourteen individuals with PD "off" and "on" medication. Results: Both healthy elderly and PD patients "off" medication displayed a top-down sequence of segment reorientation, but differed with respect to the delay time between segments: PD "off" medication displayed a shorter delay between the onset of head and shoulder reorientation and longer delays for pelvis and foot reorientation. Furthermore, for all segments the peak angular velocities were lower for PD patients than healthy controls, with greater difference between the two groups during larger turns. While for both groups the velocity and magnitude of rotation of all segments were greater during larger turns, the relative timing of reorientation of segments remained the same during small and large turns. Medication had no significant effect on the timing and sequence of reorientation of segments and caused only a small and non-significant increase to segment velocities. Conclusion: This study further characterized the turning performance of individuals with PD. Our findings have clinical applications and therapeutic value for PD patients with difficulty turning. Understanding the specific deficiencies of turning performance of PD patients allows the therapists to opt for the most effective rehabilitation techniques.
\end{abstract}

RÉSUMÉ: Maladie de Parkinson et coordination segmentaire au cours des changements de direction : I. les changements de direction sur place. Objectif : Plusieurs chutes chez les parkinsoniens surviennent pendant un changement de direction subit, sur place, qui requiert une réorientation systématique des segments axiaux vers une nouvelle direction. Nous avons examiné si une perturbation de la coordination de la réorientation segmentaire est une cause importante des difficultés éprouvées par les parkinsoniens quand ils changent de direction et si la médication dopaminergique les modifient. Méthode : La séquence et la chronologie de la réorientation segmentaire au cours de changements de direction sur place à $45^{\circ}$ et à $90^{\circ}$ ont été examinées chez 14 parkinsoniens sous médication en phase « off » et en phase « on » et chez 19 sujets témoins en bonne santé. Résultats : Quelle que soit l'ampleur du changement de direction, les sujets témoins réorientaient leur tête, leurs épaules et leur bassin simultanément et ceci était suivi d'un déplacement médio-latéral des pieds. Chez les parkinsoniens, la séquence temporelle de la coordination était semblable à celle des témoins. Cependant, au début du mouvement, la vitesse et l'ampleur de la réorientation de chaque segment corporel étaient diminuées chez les parkinsoniens. Ceci était amélioré légèrement par la médication dopaminergique. Conclusion : Notre observation que les sujets témoins et les parkinsoniens tournent en bloc quand le changement de direction est prévisible et qu'il n'existe pas de contrainte de temps démontre que la stratégie du changement de direction en bloc n'est pas en cause si les paramètres du mouvement ne sont pas exécutés sous contrainte. Cependant, dans une situation réelle, qui nécessite habituellement des changements de direction rapides et imprévisibles, la stratégie du changement de direction en bloc peut être dangereuse et plus susceptible de causer des chutes. Dans de telles situations, alors que les témoins sont capables de passer d'une stratégie en bloc à un stratégie segmentaire séquentielle, les parkinsoniens eux peuvent ne pas être capables de le faire et continuent à changer de direction en bloc.

Can J Neurol Sci. 2013; 40: 520-526

\section{INTRODUCTION}

Parkinson's disease (PD) is one of the most common neurodegenerative diseases after Alzheimer's disease ${ }^{1}$, and impaired walking is one of the main symptoms of $\mathrm{PD}^{2,3}$. Turning is even more challenging for PD patients than walking on a straight path ${ }^{4,5}$ and the incidence of freezing and falling is greater during turning ${ }^{6}$. Previous research has shown that individuals with PD turn slower ${ }^{7-11}$, make wider turns ${ }^{11}$ with narrower steps ${ }^{9,11,12}$ and take more steps to complete a turn when walking $7,12,13$.

Research has shown that the coordination of reorientation of body segments during turns while walking is impaired even in individuals with PD who demonstrate normal spatio-temporal gait parameters during straight walking and have negligible or no axial rigidity $7,8,14$. These studies have shown that when making a $90^{\circ}$ turn during walking, healthy elderly turn their head towards the new direction of travel first followed by reorientation of the upper trunk and then pelvis. Parkinson's disease patients displayed a significant delay in reorienting their head towards the new direction of travel when approaching the

From the Department of Kinesiology (SA, JSF), University of Waterloo; St. Jerome's University (JSF), Waterloo; Movement Disorders Program (MJ), London Health Sciences Centre, London, Ontario, Canada.

Received June 11, 2012. Final Revisions Submitted February 20, 2013. Correspondence to: Sakineh Akram, University of Waterloo, 200 University Avenue West, Waterloo, Ontario, N2L 3G1, Canada. Email: sbakram@uwaterloo.ca. 
turn and turned the head and upper trunk in unison, followed by reorientation of the pelvis ${ }^{7,8,14}$. The magnitude of head rotation during the turning step was significantly greater than that of the upper trunk for healthy elderly, but of similar magnitude in individuals with $\mathrm{PD}^{8}$. The magnitude of rotation of all three segments during the turning step was significantly reduced in PD participants relative to healthy elderly ${ }^{7,8}$.

Past studies of the effect of Parkinson's disease on turning behavior while walking have been limited to the "on" medication state and, most often, have limited their observations to the head and upper trunk. The purpose of this study was to examine the effect of Parkinson's disease on segment coordination when turning in both the "off" and "on" medication states; our companion paper examined on-the-spot turns in the same population in both the "off" and "on" medication states. Small $\left(45^{\circ}\right)$ and large $\left(90^{\circ}\right)$ turns were examined to determine whether disruptions to coordination are exacerbated with increased turn magnitude. Head, shoulder, pelvis and foot movements were recorded to provide a more complete picture of segment coordination.

\section{Methods}

\subsection{Participants}

Fourteen individuals with PD and nineteen age-matched healthy controls (HC) participated in this study (Table $1^{15}$ ). Patients were diagnosed with idiopathic PD by their neurologist and were free from any musculoskeletal or additional neurologic conditions. Three patients reported one fall during the six months prior to testing. Healthy controls were free from any neurological or musculoskeletal impairment, and had no history of falls in the six months prior to participating in the experiment. Participants were informed about the experimental procedure before signing a consent form. All procedures were approved by the Office of Research Ethics at the University of Waterloo and the University of Western Ontario.

\subsection{Data Collection}

Participants changed into tight-fitting clothing. Twelve infrared emitting diodes (IREDs) were mounted on the following locations of the body, bilaterally: ear, acromion process, anterior superior iliac spine, hip joint, lateral malleolus, and the big toe. One IRED was mounted on the chin and another IRED on the participant's chest approximately $5 \mathrm{~cm}$ below the jugular notch. Four Optotrak cameras (Northern Digital Inc., Canada) were used to collect kinematic data. Optotrak data were recorded at $120 \mathrm{~Hz}$.

Each participant was tested for three straight walking trials and twelve trials of walking and turning. All trials were performed with the participants' arms crossed in front of their chest. Since arm swinging is reduced in PD patients ${ }^{16}$ this approach eliminated the possible contribution of the arm swinging on the reorientation of body segments for both groups. In the straight walking trials participants were asked to walk straight ahead on a seven meters path. During turning trials participants were asked to walk straight ahead for about four meters to reach the "turning zone" and then turn off at an angle of $45^{\circ}$ or $90^{\circ}$ to either right or left and continue walking for another three meters. A circle (diameter $=50 \mathrm{~cm}$ ) was drawn on

Table 1: Participants' Characteristics

Healthy participants: $(\mathrm{n}=19,10 \mathrm{M}, 9 \mathrm{~F})$, Mean age 66 years (SD 4.2)

\begin{tabular}{|c|c|c|c|c|c|c|c|}
\hline $\begin{array}{l}\text { PD participant's } \\
\text { ID } \\
\end{array}$ & Gender & $\begin{array}{c}\text { Age } \\
\text { (year) }\end{array}$ & $\begin{array}{c}\text { PD Duration } \\
\text { (year) }\end{array}$ & Medication & $\begin{array}{c}\text { Daily Dose }^{\Delta} \\
\text { (mg) }\end{array}$ & $\begin{array}{c}\text { UPDRS } \uparrow \text { Score } \\
\text { "Off" Med }\end{array}$ & $\begin{array}{c}\text { UPDRS } \dagger \text { Score } \\
\text { "On" Med }\end{array}$ \\
\hline 1 & $\mathrm{~F}$ & 64 & 5 & Pramipexole & 201 & 30.5 & 16 \\
\hline 2 & $\mathrm{~F}$ & 57 & 4 & Levodopa/Carbidopa, Trihexyphenidyl & 400 & 38 & 32.5 \\
\hline 3 & M & 70 & 9 & Levodopa/Carbidopa & 450 & 39 & 23.5 \\
\hline 4 & $\mathrm{~F}$ & 64 & 5 & Levodopa/Carbidopa & 500 & 22 & 12.5 \\
\hline 5 & M & 67 & 6 & Levodopa/Carbidopa & 800 & 36 & 24 \\
\hline 6 & M & 70 & 2 & Rasagiline & $1^{\Omega}$ & 20.5 & 12 \\
\hline 7 & $\mathrm{~F}$ & 68 & 7 & Ropinirole & 200.04 & 13.5 & 6.5 \\
\hline 8 & M & 62 & 5 & Levodopa/Carbidopa \& Pramipexole & 401.5 & 14.5 & 6 \\
\hline 9 & $\mathrm{~F}$ & 70 & 8 & Levodopa/Carbidopa & 450 & 12 & 12 \\
\hline 10 & M & 73 & 1 & Rasagiline & $1^{\Omega}$ & 18 & 9.5 \\
\hline 11 & M & 62 & 8 & Levodopa/Carbidopa & 1000 & 29 & 20.5 \\
\hline 12 & $\mathrm{M}$ & 63 & 3 & Levodopa/Carbidopa & 400 & 19.5 & 12 \\
\hline 13 & $\mathrm{~F}$ & 70 & 5 & Levodopa/Carbidopa \& Ropinirole & 733.36 & 14 & 8 \\
\hline 14 & $\mathrm{~F}$ & 74 & 4 & Levodopa/Carbidopa & 600 & 25 & 22 \\
\hline Mean & & 67 & 5 & & & $24^{*}$ & 16 \\
\hline SD & & 4.8 & 2.3 & & & 9.4 & 7.8 \\
\hline
\end{tabular}

${ }^{\dagger}$ Unified Parkinson’s Disease Rating Scale (total motor sub-score); ${ }^{*}$ significantly different from "on" medication. ${ }^{\Delta}$ Daily dose of the levodopa equivalent of dopaminergic medications ${ }^{15} .{ }^{\Omega} 1 \mathrm{mg}$ of Rasagiline per day. Currently there is no formula for calculating the levodopa equivalent of Rasagiline. $\mathrm{PD}=$ Parkinsons disease; $\mathrm{M}=$ Male; F=Female; $\mathrm{n}=$ Number; $\mathrm{SD}=$ standard deviation 
the lab floor to indicate the "turning zone." A pylon was placed at the end of each of the potential travel paths to provide a continuous visual cue about the direction of the turn. Before each trial, participants were told towards which pylon they should walk. Participants were instructed to walk straight forward until they reach the turning zone at which point they were asked to turn into the designated path (without stopping at the turning zone) and to keep walking until they reach the pylon positioned at the end of the path. Participants were instructed not to adjust their step length to step on the turning zone. They were told that the circle was there to simply guide them as to about where they should make their turn.

Participants performed three trials of turning in each direction. However, due to the limited equipment and space, data were collected only during the right-turn trials (six trials). Participants were unaware that data were not being collected during the left-turn trials. The straight walking trials were always performed at the beginning followed by the turning trials. The order of the right-turn and left-turn trials was completely randomized. Upon completion of all the trials, participants' spinal flexibility was measured using the Functional Axial Rotation (FAR) test ${ }^{17}$. Rest periods were provided throughout the experiment upon the participants' request.

Individuals with PD were tested in "off" and "on" medication states. They were asked to skip the last dose of their dopaminergic medication on the previous day, prior to coming to the laboratory in the morning. Upon arrival, they were tested while "off" medication (12 hours). Then they were asked to take their dopaminergic medication. The second round of trials started when the participant reported that he/she was in an "on" state (at least an hour after taking the medication) $)^{18,19}$. Motor performance of individuals with PD while "off" (upon arrival) and "on" medication (just before the 2nd round of trials started) was evaluated using the motor component of the Unified Parkinson's Disease Rating Scale (UPDRS). The FAR test was also performed both "off" and "on" medication.

\subsection{Data processing}

The Optotrak data were low-pass filtered (Butterworth) prior to analyses with a cut-off frequency of $6 \mathrm{~Hz}$. For each trial and for each participant, the yaw angular displacement profiles of the head, shoulder (upper trunk), and pelvis in the global reference frame were determined from the three non-co-linear markers placed on each of the aforementioned segments. For each participant, the mean and standard deviation values of the head, shoulder, and pelvis yaw were calculated during the three straight walking trials. The initiation of reorientation of head, shoulder, and pelvis in yaw plane during a turning trial was calculated as the point in time that the angular displacement data indicated the segment had turned towards the new direction, providing the deviation continued beyond the average range of displacement of the segment during the straight walking trials.

Toe displacement profiles were used to determine the onset of change in the mediolateral foot displacement for the right and left feet. For each participant, the data obtained from the three straight walking trials were averaged. The mean and standard deviation (SD) values obtained from the straight walking trials were used as control. For the turning trials, the onset of foot mediolateral deviation into the designated travel direction was calculated as the point in time that test data deviated from the control average profile providing the deviation continued beyond the control two SD boundary.

Initiation of head reorientation was considered the reference time (0 milliseconds (ms)). Delay time (DT) refers to the delay in reorientation in the yaw plane of shoulder (DT-Shoulder), pelvis (DT-Pelvis), and the foot that deviated first towards the new direction (DT-Foot) relative to the start of head turn.

For each trial the peak yaw angular velocity after the onset of the turn was calculated for the head, shoulder and pelvis. The amount of head, shoulder and pelvis turn also was calculated over a period of time defined by the time when the segment initiated its reorientation and the onset of mediolateral foot displacement.

\subsection{Data Analysis}

\subsubsection{Effect of PD}

Due to lack of main effect for gender, this factor was removed in further analysis.

Data collected from the HC and PD patients "off" medication were used to examine the effects of PD. A three-way repeated measure analyses of variance (ANOVA) with group (HC vs. PD patients) as between factor, and segment (shoulder, pelvis, foot) and magnitude $\left(45^{\circ}, 90^{\circ}\right)$ as within factors was performed on DT-Shoulder, DT-Pelvis and DT-Foot. Since initiation of head rotation is considered as the reference time $(0 \mathrm{~ms})$, the head could not be included as a segment in the above analysis. Therefore, t-tests were performed to determine if the means of DT-Shoulder, DT-Pelvis and DT-Foot are significantly different from zero (initiation of head reorientation). A Bonferroni correction was used to correct for multiple comparisons.

The velocity and magnitude of turn achieved by the different segments at the time of onset of foot reorientation were compared across groups and turn magnitude conditions using three-way repeated measure ANOVAs with group (HC vs. PD) as between factor, and segment (head, shoulder, pelvis) and magnitude $\left(45^{\circ}, 90^{\circ}\right)$ as within factors.

\subsubsection{Effect of Dopaminergic Medications}

Data obtained from PD patients "off" and "on" medication were analyzed to examine possible effects of dopaminergic medications on segments coordination. To examine the effect of medication on the sequence and timing of reorientation of body segments during small and large turns, a three-way repeated measure ANOVA with medication condition ("off" and "on"), segment (shoulder, pelvis, foot), and magnitude of the turn $\left(45^{\circ}\right.$, $90^{\circ}$ ) as within factors was performed on the delay times of reorientation of the segments. T-tests were performed to determine if the means of the delay times of reorientation of the segments were significantly different from zero (initiation of head reorientation). A Bonferroni correction was used to correct for multiple comparisons.

The effect of medication on the velocity and the magnitude of turn achieved by each segment at the time of onset of foot reorientation was examined using a three-way repeated measure ANOVAs with medication condition ("off" and "on"), segment (head, shoulder, pelvis), and magnitude of the turn $\left(45^{\circ}, 90^{\circ}\right)$ as within factors. 
In conditions that a main or interaction effect of a factor was revealed, Tukey's Studentized Range (HSD) Test was performed to determine which means were significantly different from the others. For all tests, a significance value $(\mathrm{P})$ of less than 0.05 was used to test statistical significance.

\section{Results}

\subsection{Effect of PD (HC vs. PD “Off”)}

The sequence and timing of segment reorientation was similar for HC and PD patients "off" medication. Figure 1a reveals a top-down sequence of shoulder, pelvis and foot reorientation during both $45^{\circ}$ and $90^{\circ}$ turns for $\mathrm{HC}$ and $\mathrm{PD}$ patients "off." ANOVA revealed significant effects of segment $(\mathrm{F}(2,62)=216.96, \mathrm{P}<0.0001)$ and group*segment $(\mathrm{F}(2,62)=9.66$, $\mathrm{P}=0.0002)$. Turn magnitude did not influence the delay time of segment reorientation for either of the groups.

Post hoc analysis of the group*segment interaction revealed that when averaged across turn amplitudes (Figure 1b), PD "off" displayed greater delays in initiation of pelvis $(357 \pm 352 \mathrm{~ms}$ vs. $248 \pm 216 \mathrm{~ms})$ and foot reorientation $(960 \pm 213 \mathrm{~ms}$ vs. $721 \pm 250$ ms) than HC. When averaged across turn amplitudes, PD patients "off" displayed an earlier initiation of shoulder turn than HC $(91 \pm 158 \mathrm{~ms}$ vs. $164 \pm 224 \mathrm{~ms})$; however, this difference was not significant (Figure 1b). The delay time of the shoulders relative to the initiation of the head turn was significantly different from zero for both $\mathrm{HC}(\mathrm{t}=4.51, \mathrm{P}<0.0001)$ and $\mathrm{PD}$ patients "off" ( $\mathrm{t}=3.03, \mathrm{P}=0.0053)$, when averaged across turn magnitudes.

Figure 2 reveals a consistently lower velocity of head, shoulder and pelvis reorientation for PD patients "off" and an increase in velocity for all segments for larger turns. The ANOVA revealed significant effects of group $(\mathrm{F}(1,31)=47.17$, $\mathrm{P}<0.0001)$, segment $(\mathrm{F}(2,62)=4.55, \mathrm{P}=0.01)$, magnitude $(\mathrm{F}(1,31)=475.95, \mathrm{P}<0.0001)$, group*magnitude $(\mathrm{F}(1,31)=31.14$, $\mathrm{P}<0.0001)$, group*segment $(\mathrm{F}(2,62)=4.00, \mathrm{P}=0.0232)$, and segment*magnitude $(\mathrm{F}(2,62)=12.73, \mathrm{P}<0.0001)$ on the velocity values. The peak velocity was significantly smaller during the $45^{\circ}$ turns than during the $90^{\circ}$ turns for both groups and across all body segments.

The significant group*magnitude interaction effect was due to the greater difference in all segment velocities between the

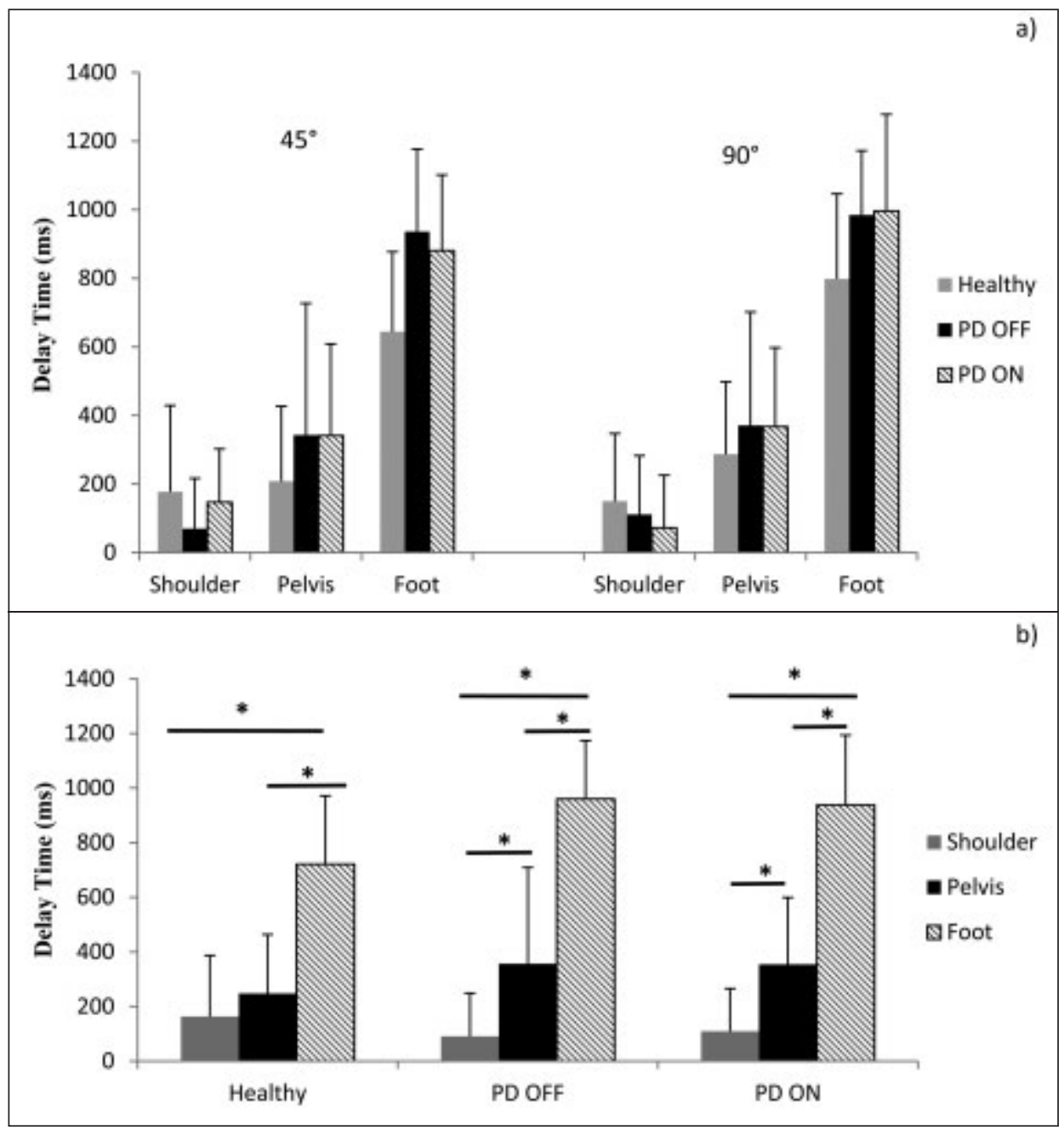

Figure 1: Mean and standard deviation (error bars) of the delays in initiation of reorientation of shoulder, pelvis and foot during $45^{\circ}$ and $90^{\circ}$ turns (a), and averaged across the two magnitudes of turn (b) for healthy controls and individuals with Parkinson's disease "off" and "on" medication. Stars indicate significant differences $(\alpha=0.05)$. 


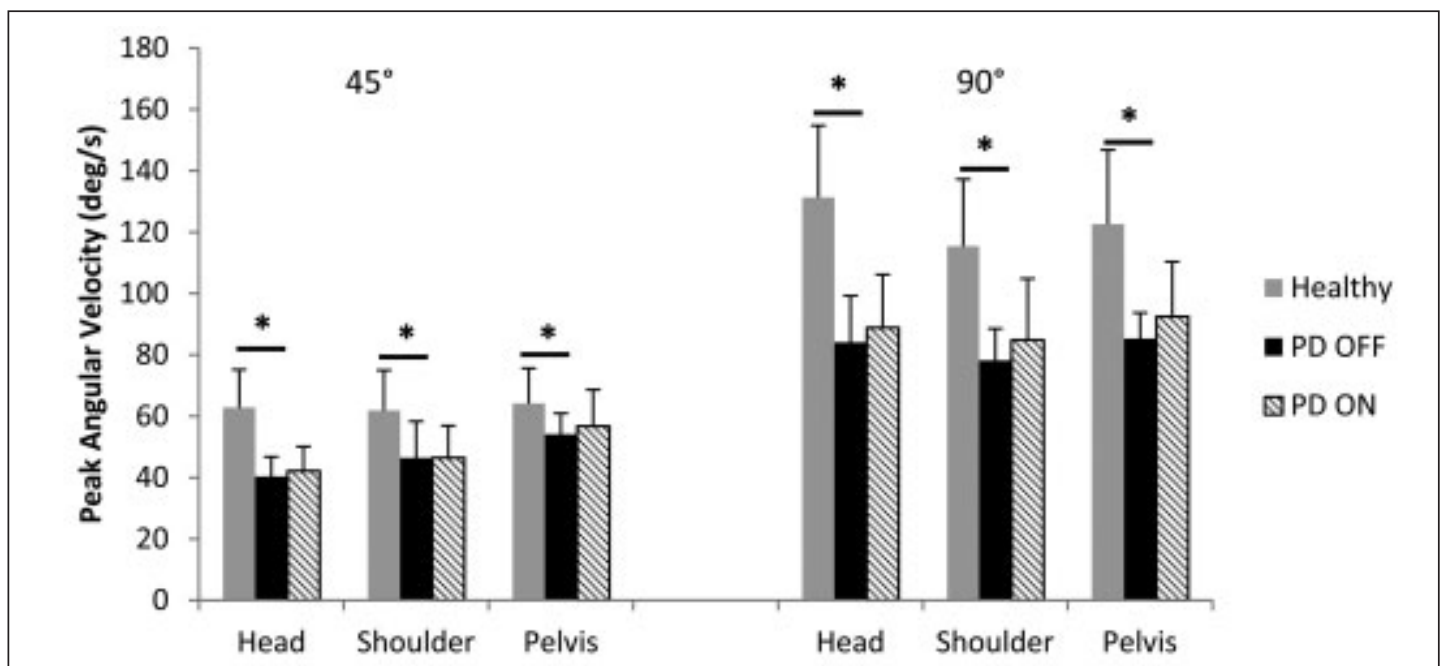

Figure 2: Mean and standard deviation (error bars) of the peak velocity of head, shoulder and pelvis during $45^{\circ}$ and $90^{\circ}$ turns for healthy controls and people with Parkinson's disease "off" and "on" medication. Stars indicate significant differences $(\alpha=0.05)$.

two groups during the $90^{\circ}$ turns than the $45^{\circ}$ turns (Figure 2). The group*segment interaction effect revealed that head velocity exceeded the shoulder and pelvis velocity for $\mathrm{HC}$, while the pelvis velocity exceeded shoulder and head velocity for PD "off" patients.

Figure 3 displays the rotation magnitude of each segment at the time of onset of foot reorientation; this was similar for $\mathrm{HC}$ and PD "off"patients, but differed across segments and between turn magnitudes. The ANOVA revealed a significant effect of segment $(\mathrm{F}(2,62)=38.69, \mathrm{P}<0.0001)$, magnitude $(\mathrm{F}(1,31)=52.20$, $\mathrm{P}<0.0001)$, and segment $*$ magnitude $(\mathrm{F}(2,62)=28.13, \mathrm{P}<0.0001)$ on the amount of turn achieved at the time of onset of foot reorientation. The amount of turn was significantly smaller for all body segments during the $45^{\circ}$ turns than during $90^{\circ}$ turns; but the pattern across segments differed for $45^{\circ}$ versus $90^{\circ}$ turns. During $45^{\circ}$ turns, the amount of head turn exceeded the shoulders and pelvis and the amount of shoulder and pelvis turn was similar. During $90^{\circ}$ turns, all segments differed: the amount of head turn exceeded the shoulders and the amount of shoulders turn exceeded the pelvis. Group had no main or interaction effect on the degree of turn achieved by any segment at the time of onset of foot reorientation.

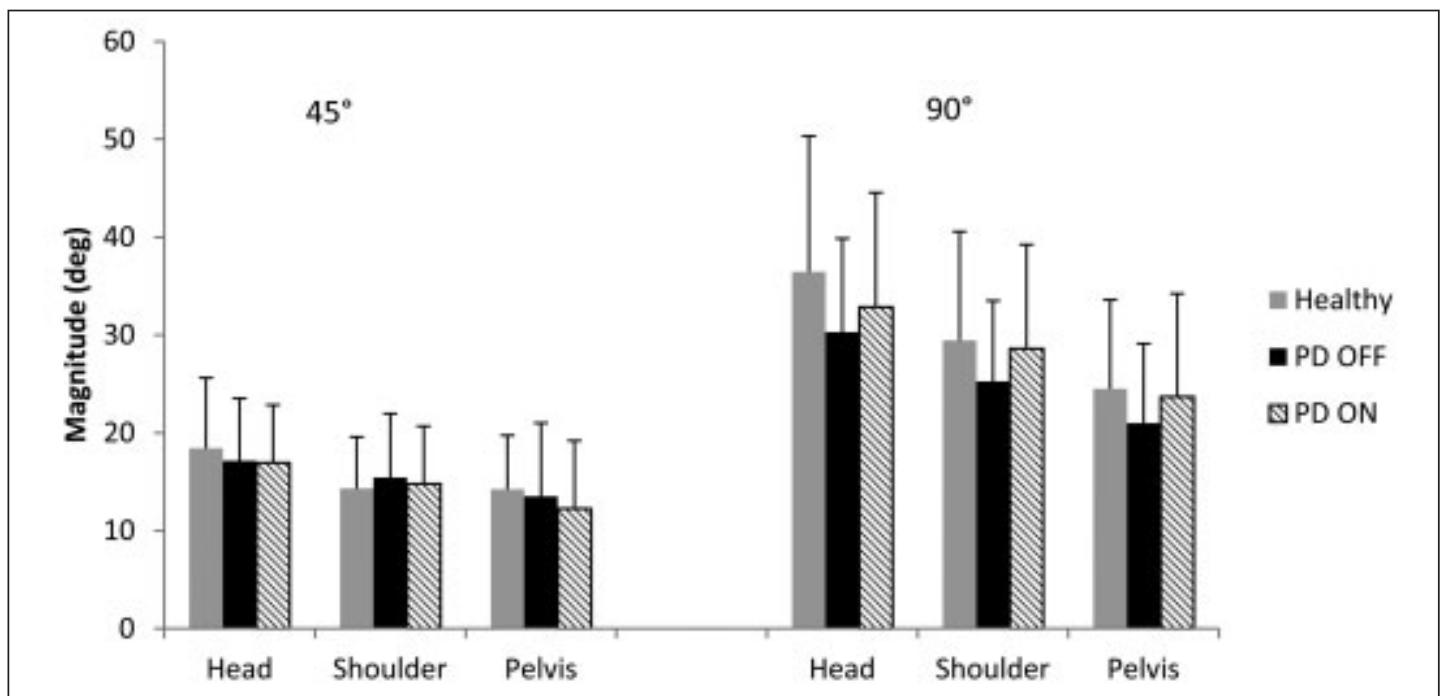

Figure 3: Mean and standard deviation (error bars) of the amplitude of head, shoulder and pelvis turn at the time of onset of foot reorientation during $45^{\circ}$ and $90^{\circ}$ turns for healthy controls and individuals with Parkinson's disease "off" and "on" medication. 


\subsection{Effect of medication (PD patients “Off” vs. “On”)}

Figures 1 through 3 display the results of PD patients "on" medication, alongside measures of PD patients "off" medication. ANOVA revealed no significant main or interaction effect of medication on the sequence and timing of segmental reorientation. Regardless of the medication condition, reorientation of body segments followed a top-down sequence with significant delays among onset of reorientation of head, shoulder, pelvis, and foot. Medication caused a small and nonsignificant increase on the segment velocities and the magnitude of turn achieved at the time of onset of foot reorientation only during the $90^{\circ}$ turns.

The Functional Axial Rotation scores revealed no difference between HC and PD patients "off" medication, and between PD patients "off" and "on" medication (Table 2).

\section{Discussion}

We examined the coordination of head, shoulder, pelvis and foot reorientation in healthy elderly and individuals with PD "off" and "on" medication as they made two different magnitudes of turn while walking. Both healthy elderly and PD individuals "off" medication displayed a top-down sequence of segment reorientation when turning while walking, but differed with respect to the delay time between segments: the PD "off" group displayed longer delay times for pelvis and foot reorientation. Larger turns were accompanied by an increase in the peak velocity and magnitude of rotation of all segments for both groups; however, the relative timing of reorientation of the segments remained the same. A comparison of PD individuals "off" versus "on" medication revealed no effect of medication on any of the performance measures.

Our study is the first to examine the influence of Parkinson's disease, during both "off" and "on" medication states, on segmental coordination during turning while walking. Past studies limited their examination of PD effects on turning behavior when walking to the "on" medication state and their reports vary. Ferrarin et $\mathrm{al}^{14}$ and Crenna et $\mathrm{al}^{8}$ limited their observations to the head and upper trunk and reported blocked control of these segments. Carpinella et $\mathrm{al}^{7}$ also reported blocked turning of the head and upper trunk, followed by reorientation of the pelvis. The findings of Mak et $\mathrm{al}^{9}$ and Huxam et $\mathrm{al}^{20}$ differ from these reports and are similar to our report of a top-down sequence. Mak et $\mathrm{al}^{9}$ reported a top-down sequence similar to our findings. Huxam et $\mathrm{al}^{20}$ reported an initial turning of the head, followed by blocked turning of the trunk and pelvis and a later reorientation of the feet. The blocked rotation of the upper trunk and pelvis reported by Huxam et $\mathrm{al}^{20}$ may be a strategy adopted by PD participants to simplify circumventing the obstacle (post), that defined the turn location. Our study and that of Mak et $\mathrm{al}^{9}$ did not define the turn location with an obstacle, but rather marked the turn location on the floor along the walking path.

While PD participants, both "off" and "on" medication, displayed a top-down pattern of coordination when turning while walking, the sequence timing was lengthened and rotations were slower relative to that of healthy controls. Relative to the $\mathrm{HC}$ group, the delay for pelvis and foot reorientation was lengthened (248 ms vs. $357 \mathrm{~ms}$ and $721 \mathrm{~ms}$ vs. $960 \mathrm{~ms}$, for HC and PD, respectively). The peak angular velocity of segments also differed for $\mathrm{HC}$ and PD participants. Peak angular velocities were lower across all segments for PD patients compared to $\mathrm{HC}$ participants and the velocity pattern across segments differed: $\mathrm{HC}$ rotated the head slightly faster than the shoulder and pelvis, while PD participants displayed the reverse pattern. Visser et al ${ }^{10}$ also reported smaller trunk peak yaw and roll velocities for PD patients than $\mathrm{HC}$ during turns embedded in locomotion. This slowing may reflect bradykinesia or an attempt to limit the destabilizing influence of angular momentum. The relatively faster rotation of the pelvis for PD participants may be a compensation for the delayed initiation of turning of this segment, i.e. the pelvis must be reoriented faster to catch-up with the shoulders and prepare for reorientation of the feet.

While the group with PD turned more slowly, the magnitude of reorientation of body segments at the onset of foot reorientation did not differ from the $\mathrm{HC}$ group. These results are in agreement with findings of Huxham and colleagues ${ }^{20}$ who showed that individuals with PD are able to adequately rotate their body segments during turning. In fact, the magnitude of rotation of body segments measured at the same distances relative to the turning point was reported to be greater in $\mathrm{PD}$ patients than in $\mathrm{HC}^{20}$.

Medication had no significant effect on the turning performance of the PD group: the timing, sequence, and magnitude of reorientation of the body segments remained the same "off" and "on" medication. We are not aware of any other study that has examined the coordination of body segments during walking turns in PD individuals "off" versus "on" medication. Hong and colleagues ${ }^{21}$ examined the performance of

Table 2: Functional Axial Rotation (FAR) scores

\begin{tabular}{|c|c|c|c|c|c}
\hline \multicolumn{2}{c|}{ PD Participants (n=14) } & \multicolumn{2}{c}{ Healthy Participants (n=19) } \\
\cline { 1 - 3 } “off” medication & "son” medication & Head & Shoulder \\
\hline \multirow{2}{*}{ Head } & Shoulder & Head & Shoulder & $100 \pm 13$ & $43 \pm 10$ \\
\hline
\end{tabular}

FAR scores (degree) of individuals with Parkinson disease "off" and "on" medication and healthy controls. Scores are the average of the scores for the right and left side rotations. 
individuals with PD patients "off" versus "on" medication during on-the-spot turns; similar to our finding, they reported no significant effect of medication on the relative timing and amplitude of rotation of body segments. The lack of medication effect on coordination of axial segmental reorientation is consistent with reports that dopaminergic medications are less effective in alleviating the axial signs of $\mathrm{PD}^{22,23}$.

\section{CONCLUSIONS}

Clinicians often describe the coordination pattern of body segments when turning as top-down, sequential for healthy individuals and as en bloc for individuals with Parkinson's disease. A number of research reports dispute this description ${ }^{9,24}$; however, none provide a comprehensive examination of on-thespot and walking turns in individuals with Parkinson's disease when both "off" and "on" medication. Our companion studies are the first to provide this comprehensive analysis.

The findings of our companion studies reveal four clinically important observations. First, the sequence of body segment coordination is preserved with $\mathrm{PD}$. Both the $\mathrm{HC}$ and the PD group revealed an en bloc reorientation of the head, shoulders and pelvis during on-the-spot turns and a top-down sequential pattern during walking turns. Second while the pattern of coordination is preserved with $\mathrm{PD}$, timing is disrupted during walking turns; the delay time for reorientation of the pelvis and foot was prolonged relative to the onset of head reorientation. Third, the velocity of rotation of body segments is reduced with PD during both types of turns; however, both HC and PD participants were able to increase velocity when performing larger magnitude turns. This finding reflects the general slowing of movement, i.e. bradykinesia, in Parkinson's disease. Fourth, anti-Parkinson medication has no effect on the coordination and velocity of turning during either on-the-spot or walking turns. This finding is consistent with reports of limited effect of antiParkinson medications on the performance of axial movements ${ }^{22,23}$.

Our findings are limited to turns performed toward predictable target locations and at a self-selected pace. Since the pattern of coordination largely was preserved in PD, turns under these conditions may pose little risk to falling. Turns performed toward unanticipated target locations, at a faster pace and/or when dual-tasking are likely to increase the risk of a fall. Further research should focus on examining influence of PD on the coordination of body segments during turning under these more challenging conditions.

\section{ACKNOWLEDGEMENT}

The authors would like to acknowledge the Natural Sciences and Engineering Research Council (NSERC) and Ontario Neurotrauma Foundation (ONF) for the funding of this research.

\section{REFERENCES}

1. Schapira AH. Science, medicine, and the future: Parkinson's disease. BMJ. 1999;318:311-4.

2. Blin O, Ferrandez AM, Pailhous J, Serratrice G. Dopa-sensitive and dopa-resistant gait parameters in Parkinson's disease. J Neurol Sci. 1991;103:51-4.

3. Delong MR. The Basal Ganglia. In: Kandel ER, Schwartz JH, Jessel TM, editors. Principles of neural science. New York: McGrawHill; 2000. P. 832-67.
4. Bloem BR, Grimbergen YA, Cramer M, Willemsen M, Zwinderman AH. Prospective assessment of falls in Parkinson's disease. J Neurol. 2001;248:950-8.

5. Giladi N, McMahon D, Przedborski S, Flaster E, Guillory S, Kostic $\mathrm{V}$, Fahn S. Motor blocks in Parkinson's disease. Neurology. 1992;42:333-9.

6. Stack EL, Ashburn AM, Jupp KE. Strategies used by people with Parkinson's disease who report difficulty turning. Parkinsonism Relat Disord. 2006;12:87-92.

7. Carpinella I, Crenna P, Calabrese E, et al. Locomotor function in the early stage of Parkinson's disease. IEEE Trans Neural Syst Rehabil Eng. 2007;15:543-51.

8. Crenna P, Carpinella I, Rabuffetti M, et al. The association between impaired turning and normal straight walking in Parkinson's disease. Gait Posture. 2007;26:172-8.

9. Mak MK, Patla A, Hui-Chan C. Sudden turn during walking is impaired in people with Parkinson's disease. Exp Brain Res. 2008;190:43-51.

10. Visser JE, Voermans NC, Oude Nijhuis LB, et al. Quantification of trunk rotations during turning and walking in Parkinson's disease. Clin Neurophysiol. 2007;118:1602-6.

11. Willems AM, Nieuwboer A, Chavret F, et al. Turning in Parkinson's disease patients and controls: the effect of auditory cues. Mov Disord. 2007;22:1871-8.

12. Morris ME, Huxham F, McGinley J, Dodd K, Iansek R. The biomechanics and motor control of gait in Parkinson disease. Clin Biomech. 2001;16:459-70.

13. Schenkman M, Morey M, Kuchibhatla M. Spinal flexibility and balance control among community-dwelling adults with and without Parkinson's disease. J Gerontol A Biol Sci Med Sci. 2000;55:M441-5.

14. Ferrarin M, Carpinella I, Rabuffetti M, Calabrese E, Mazzoleni P, Nemni R. Locomotor disorders in patients at early stages of Parkinson's disease: a quantitative analysis. Conf Proc IEEE Eng Med Biol Soc. 2006;1:1224-7.

15. Hobson DE, Lang AE, Martin WR, Razmy A, Rivest J, Fleming J. Excessive daytime sleepiness and sudden-onset sleep in Parkinson disease: a survey by the Canadian Movement Disorders Group. JAMA. 2002;287:455-63.

16. Martin JP. The basal ganglia and posture. London: Pitman; 1967.

17. Schenkman ML, Clark K, Xie T, Kuchibhatla M, Shinberg M, Ray L. Spinal movement and performance of a standing reach task in participants with and without Parkinson disease. Phys Ther. 2001;81:1400-11.

18. Horak FB, Frank J, Nutt J. Effects of dopamine on postural control in parkinsonian subjects: scaling, set, and tone. J Neurophysiol. 1996;75:2380-96.

19. Mancini M, Rocchi L, Horak FB, Chiari L. Effects of Parkinson's disease and levodopa on functional limits of stability. Clin Biomech. 2008;23:450-8.

20. Huxham F, Baker R, Morris ME, Iansek R. Head and trunk rotation during walking turns in Parkinson's disease. Mov Disord. 2008; 23:1391-7.

21. Hong M, Earhart GM. Effects of medication on turning deficits in individuals with Parkinson's disease. J Neurol Phys Ther. 2010; 34:11-6.

22. Bejjani BP, Gervais D, Arnulf I, et al. Axial parkinsonian symptoms can be improved: the role of levodopa and bilateral subthalamic stimulation. J Neurol Neurosurg Psychiatry. 2000;68:595-600.

23. Mesure S, Azulay JP, Pouget J, Amblard B. Strategies of segmental stabilization during gait in Parkinson's disease. Exp Brain Res. 1999;129:573-81.

24. Anastasopoulos D, Ziavra N, Savvidou E, Bain P, Bronstein AM. Altered eye-to-foot coordination in standing parkinsonian patients during large gaze and whole-body reorientations. Mov Disord. 2011;26:2201-11. 